\title{
Benign intramammary and axillary lesions mimicking malignancy
}

\author{
Bertschinger, K ; Caduff, R ; Kubik-Huch, R A
}

DOI: https://doi.org/10.1007/s003300051058

Posted at the Zurich Open Repository and Archive, University of Zurich ZORA URL: https://doi.org/10.5167/uzh-155822

Journal Article

Published Version

Originally published at:

Bertschinger, K; Caduff, R; Kubik-Huch, R A (2000). Benign intramammary and axillary lesions mimicking malignancy. European Radiology, 10(6):1029-1030.

DOI: https://doi.org/10.1007/s003300051058 


\section{Benign intramammary and axillary lesions mimicking malignancy}

\section{Sir,}

Whereas magnetic resonance imaging has a high sensitivity for malignant lesions, the lack of specificity is a known disadvantage. We describe the case of a patient in whom a benign intramammary lesion and axillary ectopic breast parenchyma in an otherwise involuted breast mimicked invasive breast carcinoma with lymph node metastases.

In our case, a 57-year-old woman presented with a 4-cm firm, painless and mobile mass in the right axilla. Mammograms showed clustered microcalcifications within an opacity in the right otherwise completely involuted breast as well as multiple large round opacities in the right axillary region suspicious of breast carcinoma with lymph node metastases (Fig.1). On MR mammography there was a $1.5-\mathrm{cm}$ strong focal and early (100\% relative signal intensity increase) contrast-enhancing lesion in the right breast coincident with the opacity with microcalcifications on the mammograms. In addition, multiple large lesions in the right axilla with, however, only moderate and inhomogeneous contrast enhancement, were seen (Fig. 2).

Preoperatively, the clustered microcalcifications in the opacity were marked under conventional mammography guidance and lumpectomy with axillary revision was done. Histological examination of the breast mass showed a fatty involuted breast tissue containing parenchymatous islands with foci of prominent intraductal, partially atypical hyperplasia with microcalciffcation, sclerosing adenosis and multiple cysts. The axillary mass presented as fibrotic breast tissue including some cysts, apocrine metaplasia and fiboadenomatous spots.

On MR mammography breast cancer demonstrates a faster and stronger postcontrast signal intensity increase compared with benign lesions. Nevertheless, this concept is not universally applicable because there are rapidly enhancing benign lesions and, rarely, slowly enhancing breast cancers $[1,2]$. Furthermore, in premenopausal women, focal contrast-enhancing lesions can occur without any underlying pathology, probably corresponding to that part of the parenchymal tissue where hormonal influence is visible [3].

In our patient there was strong evidence of malignancy not only on MR imaging, but also on mammograms. Furthermore, lymph nodes metastases were suspected on clinical and imaging grounds; however, those were mimicked by ectopic fibrotic breast parenchyma.

Ectopic breast tissue may be seen along the line corresponding to the primitive milk streak. The presence of accessory breast tissue is uncommon. The axilla is the most frequent site of presentation followed by the vulva [1]. The ectopic breast tissue responds in the same way to hormones as the normal breast parenchyma. Pathological changes that occur in normally positioned breast may develop in ectopic breast tissue, e. g. fibrocystic changes, mastitis, fibroadenoma and carcinoma [4].

In summary, this case should remind clinicians and radiologists that even if mammogram and MR findings are in accordance and give strong evidence for breast carcinoma, a benign diagnosis may still be present.
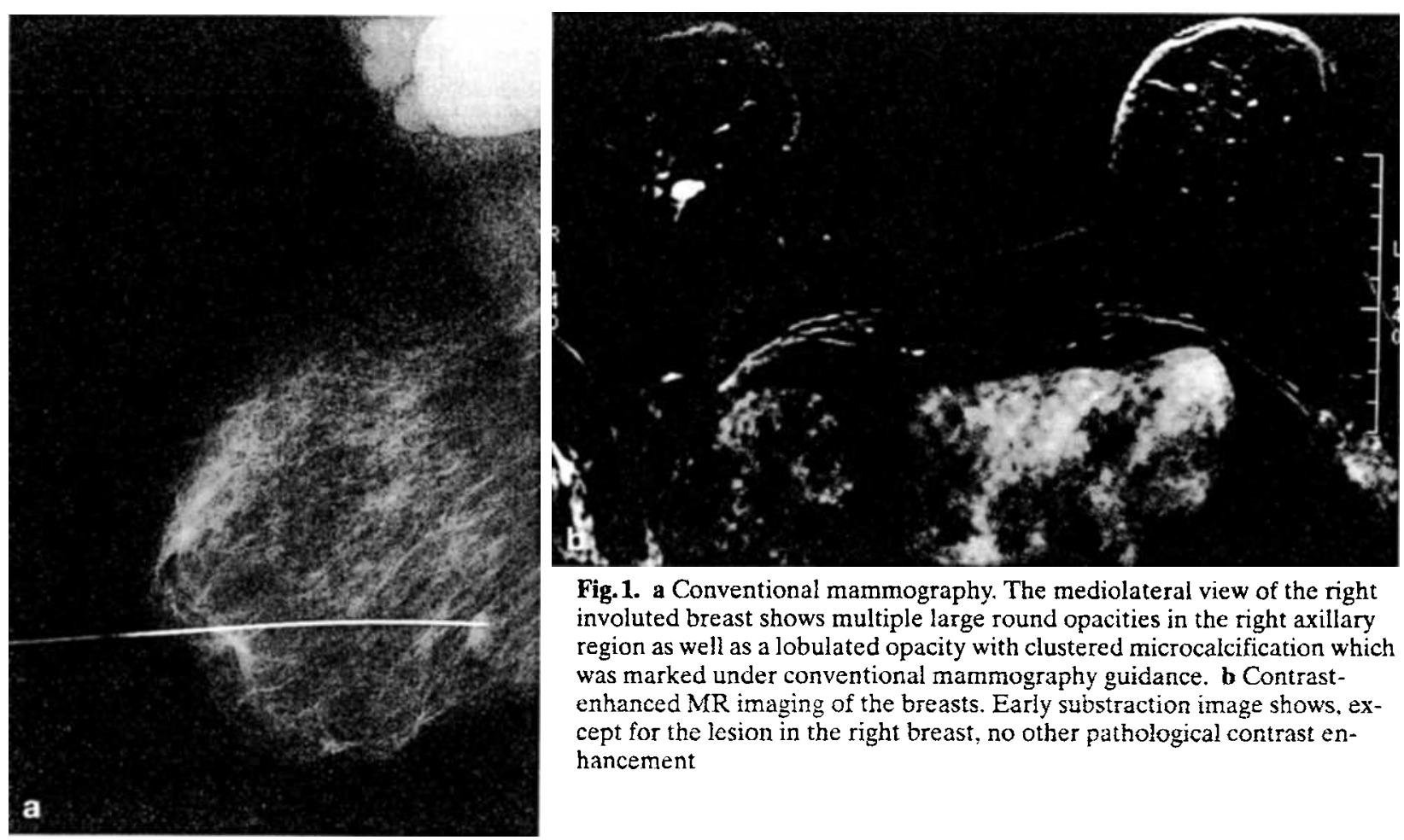

Fig.1. a Conventional mammography. The mediolateral view of the right involuted breast shows multiple large round opacities in the right axillary region as well as a lobulated opacity with clustered microcalcification which was marked under conventional mammography guidance. b Contrastenhanced MR imaging of the breasts. Early substraction image shows, except for the lesion in the right breast, no other pathological contrast enhancement 


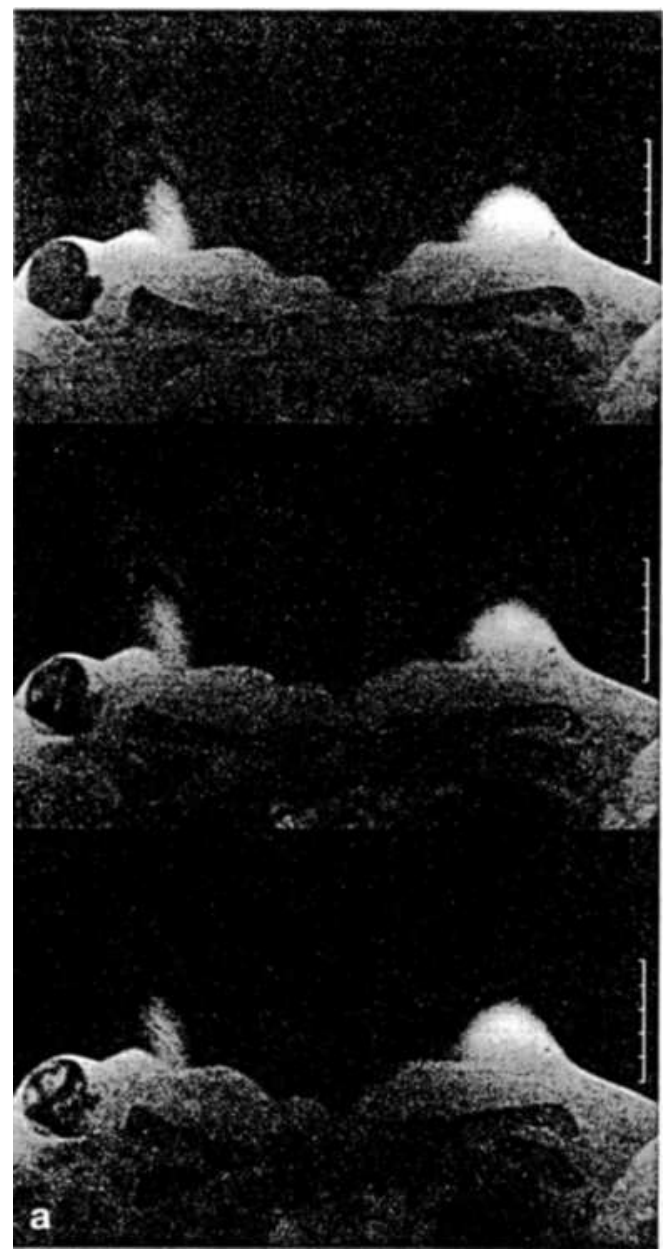

\section{References}

1. Heywang-Köbrunner SH (1994) Contrast-enhanced MR imaging of the breast. Invest Radiol: 94-104

2. Heywang-Köbrunner SH, Beck R (1996) Contrast-enhanced MR imaging of the breast. Springer, Berlin Heidelberg New York, p 5

3. Heywang-Köbrunner SH, Wolf A, Pruss E, Hilbertz T, Eiermann W, Permanetter W (1989) MR imaging of the breast with Gd-DTPA: use and limitations. Radiology 171: 491-494

4. De Choinoky T (1951) Accessory breast tissue in the axilla. NY State J Med 51: 2245-2248
Fig. 2. a Dynamic contrast-enhanced MR imaging of the reasts and axillary region. Multiple nodes, the largest $3.5 \mathrm{~cm}$ st enhancement. b Fibrotic ectopic axillary breast tissue with some regular acini (arrow), and adjacent dilated terminal intralobular ductule (haematoxylin-eosin $\times 70$ )
K. Bertschinger ${ }^{1}$, R. Caduff ${ }^{2}$, R. A. Kubik-Huch ${ }^{1}$

${ }^{1}$ Department of Radiology, University Hospital, Rämistrasse 100, CH-8091 Zurich, Switzerland

${ }^{2}$ Department of Pathology, University Hospital, Rämistrasse 100 , $\mathrm{CH}-8091$ Zurich, Switzerland 